\title{
Flexible heteroarotinoid (Flex-Het) SHetA2 inhibits angiogenesis in vitro and in vivo
}

\author{
Tashanna Myers • Shylet Chengedza • Stan Lightfoot • \\ Yanfang Pan • Daynelle Dedmond $\cdot$ Lauren Cole • \\ Yuhong Tang $\cdot$ Doris M. Benbrook
}

Received: 4 August 2008 / Accepted: 27 August 2008/Published online: 18 September 2008

(C) The Author(s) 2008. This article is published with open access at Springerlink.com

Summary Flexible heteroarotinoids (Flex-Hets) compounds regulate growth, differentiation and apoptosis in cancer cells. The hypothesis of this study was that the lead Flex-Het, SHetA2, inhibits angiogenesis by blocking cytokine release from cancer cells. SHetA2 altered secretion of thrombospondin-4 (TSP-4), vascular endothelial growth factor A (VEGF) and fibroblast growth factor (bFGF) proteins from normal and cancerous ovarian and renal cultures. Thymidine phosphorylase (TP) expression was inhibited in cancer, but not normal cultures. Endothelial tube formation was stimulated by conditioned media from cancer but not normal cultures, and SHetA2 reduced secretion of

Tashanna Myers, Shylet Chengedza, Stan Lightfoot, and Yanfang Pan contributed equally to this research.

T. Myers $\cdot$ D. Dedmond $\cdot$ D. M. Benbrook $(\bowtie)$

Department of Obstetrics and Gynecology,

University of Oklahoma Health Sciences Center,

975 N.E. 10th Street, Room 1372,

Oklahoma City, OK 73104, USA

e-mail: Doris-Benbrook@ouhsc.edu

T. Myers

e-mail: Tashanna-Myers@ouhsc.edu

D. Dedmond

e-mail: daynelle.dedmond@usoncology.com

S. Chengedza $\cdot$ Y. Pan · D. M. Benbrook

Department of Biochemistry and Molecular Biology,

University of Oklahoma Health Sciences Center,

Oklahoma City, OK 73104, USA

S. Chengedza

e-mail: Shylet-Chengedza@ouhsc.edu

Y. Pan

e-mail: Yanfang-Pan@ouhsc.edu this angiogenic activity. SHetA2 directly inhibited endothelial cell tube formation and proliferation through G1 cell cycle arrest, but not apoptosis. Recombinant TP reversed SHetA2 anti-angiogenic activity. SHetA2 inhibition of in vivo angiogenesis was observed in Caki-1 renal cancer xenografts. In conclusion, SHetA2 inhibits angiogenesis through alteration of angiogenic factor secretion by cancer cells and through direct effects on endothelial cells.

Keywords Angiogenesis · Vascular endothelial growth factor - Thymidine phosphorylase - Basic fibroblast growth factor $\cdot$ Thrombospondin $4 \cdot$ Heteroarotinoid

\author{
S. Lightfoot $\cdot$ L. Cole \\ Department of Pathology, \\ University of Oklahoma Health Sciences Center, \\ Oklahoma City, OK 73104, USA \\ S. Lightfoot \\ e-mail: Stan-Lightfoot@ouhsc.edu \\ L. Cole \\ e-mail: Lauren-Cole@ouhsc.edu \\ Y. Tang \\ Oklahoma Medical Research Foundation (OMRF), \\ 825 N.E. 13th Street, \\ Oklahoma City, OK 73401, USA \\ Present address: \\ Y. Tang \\ Samuel Roberts Noble Foundation, \\ 2510 Sam Noble Parkway, \\ Ardmore, OK 73401, USA \\ e-mail: ytang@noble.org
}




\section{Introduction}

Ovarian and renal cancers are two of the most lethal cancers with the poor mortality linked to late stage of diagnosis and to poor response to chemotherapy and development of resistance [1]. Due to the highly vascularized nature of these cancers, anti-angiogenic strategies are actively being pursued to improve the dismal patient outcome $[2,3]$. Therapeutic strategies that target the neovasculature of tumors have shown modest results [4]. Issues of these antiangiogenesis drugs with regard to toxicity and avoiding interference with standard chemotherapy are currently under intense investigation. Therapeutic strategies that target both cancer and endothelial cells within a tumor will be effective if they can be administered in a manner that does not shut down the neovasculature before the drug can access and kill the cancer cells. Drugs that target the neovasculature without affecting the cancer cells may be able to prevent growth and metastases of the cancer, but may not be able to completely eliminate the cancer, unless the population of cancer cells has a sufficiently high apoptosis rate to completely overwhelm the proliferation rate.

Endothelial cells that form the neovasculature of tumors share many signaling pathways with cancer cells and some established anti-cancer drugs, such as taxol, have been found to have anti-angiogenesis activity [5]. Thus, in the development of new anti-cancer drugs, evaluation of potential anti-angiogenesis effects should be taken into consideration for guidance in optimizing the strategy for clinical administration in order to take advantage of any anti-angiogenic effects and take into consideration potential toxicities associated with anti-angiogenesis activity.

Heteroarotinoids (Hets) represent a novel class of small molecule drugs with promising anti-cancer activity that were originally derived from the arotinoid class of retinoids by insertion of a heteroatom into the cyclic ring of arotinoids. Arotinoids proved to be 1,000 -fold more toxic than the natural retinoid, all-trans retinoic acid ( $t$-RA), while the heteroatom was found to decrease the toxicity of Hets 1,000-fold back to similar levels as $t$-RA [6]. Through structure activity relationship studies, a series of Hets that exhibit promising in vivo anti-cancer activity were developed [6-10]. A more potent class of Hets were developed by substitution of the two atom linker with a more flexible urea or thiourea linker to produce Flexible Hets (Flex-Hets). Similar to arotinoids and conventional Hets, Flex-Hets inhibited cell growth and induced differentiation, but in contrast to the parent compounds, were potent inducers of apoptosis through a mechanism independent of the retinoic acid receptors $[8,11]$. The lack of receptor activation is consistent with the lack of skin irritancy and teratogenicity of Flex-Hets [12, 13]. Studies using matching sets of cancer cell lines and normal cells derived from the same organ (ovary, kidney and endometrium), demonstrated that normal cells are much more resistant to Flex-Het apoptosis in comparison to the corresponding cancer cell lines (Liu et al. 2008 , in preparation) $[14,15]$.

The Flex-Het containing a sulfur heteroatom, a thiourea linker and an $\mathrm{NO}_{2}$ component, SHetA2 [(4-nitrophenyl) amino][2,2,4,4-tetramethylthiochroman-6-yl)amino]methane-thione], was chosen as the lead based on the greatest levels of efficacy and potency of growth inhibition activity across all cell lines tested, while retaining the differential reduced effect on normal cultures. The differential effect of SHetA2 on cancer versus normal cells was associated with direct targeting of mitochondria and decrease of Bcl-2 and $\mathrm{Bcl}_{\mathrm{xl}}$ proteins in cancer cells with little effect on normal cells [15]. Promising in vivo anticancer activity [12] and the ability to inhibit the development of cancer in an organotypic model [16] prompted the acceptance of SHetA2 into the National Cancer Institute's RAID (Rapid Access to Intervention Development, NSC 72689) and RAPID (Rapid Access to Preventive Intervention Development) programs for preclinical development as a therapeutic and chemopreventive agent for cancer, respectively.

Microarray analysis of ovarian cancer organotypic cultures identified 44 genes to be significantly regulated by SHetA2. One of the down-regulated genes, Thymidine Phosphorylase (TP), also known as platelet-derived endothelial cell growth factor (PD-ECGF), is a known antiangiogenic growth factor. The TP enzyme is involved in the nucleotide salvage pathway important for cell proliferation by converting thymidine to thymine and 2-deoxy-D-ribose1-phosphate. The latter metabolite and subsequent metabolite 2-deoxy-D-ribose have been shown to be responsible for the angiogenic activity of TP [17], while 2-deoxyL-ribose and the TP enzyme activity inhibitor CIMU (5chloro-6(1-imidazolylmethyl)uracil) could prevent the angiogenic stimulating activity of TP [17]. Administration of TP was demonstrated to enhance tumor progression and to protect cells against hypoxia induced apoptosis [18]. Higher levels of TP expression were observed in a variety of tumor types in comparison to surrounding normal tissues and appeared to be correlated with poor patient prognosis [19].

Another of the SHetA2 down-regulated genes that has potential angiogenesis regulating activity was thrombospondin 4 (TSP-4). Initially, TSP-4 was not considered to be anti-angiogenic because it lacks the protein structures in TSP-1 called type 1 repeats that are responsible for the antiangiogenesis mechanism [20, 21]. TSP-4 may be antiangiogenic however, in that it contains the type III repeats found in TSP-1 that have recently been reported to inhibit binding of FGF-2 to endothelial cells, a process that leads to endothelial cell proliferation in vitro [22]. 
The objective of this study was to determine if SHetA2 exhibited anti-angiogenic activity. It was hypothesized that altered expression of TP and TSP-4, in addition to the well-characterised angiogenic cytokines vascular endothelial cell growth factor (VEGF) and basic fibroblast growth factor (bFGF) would upset the balance of pro- and antiangiogenic factors secreted by cancer cells resulting a net alteration in angiogenesis regulating activity. In addition, it was hypothesized that SHetA2 would directly inhibit growth and differentiation of endothelial cells, which would interfere with their ability to form and maintain vascular structures.

\section{Materials and methods}

\section{Cell lines and drugs}

The A2780 (Michael Birrer, National Cancer Institute) and OVCAR-3 (ATCC) ovarian cancer cell lines were maintained in RPMI media supplemented with $1 \mathrm{mM}$ sodium pyruvate, $10 \mathrm{mM}$ HEPES, 10\% fetal bovine serum (FBS) and antibiotic/antimycotic. IOSE-80 (Michael Birrer) cells were cultured in IOSE Growth Media consisting of 1:1 Medium 199:MCDB105 supplemented with 15\% FBS. McCoy's medium supplemented with $10 \%$ FBS, antibiotic and antimycotic was used to culture the Caki-1 cell line (ATCC) derived from a human skin metastatic lesion of a renal clear cell carcinoma and the HK-2 cell line (human kidney 2 from ATCC), which is a proximal tubular cell (PTC) line derived from normal kidney and immortalized with human papillomavirus 16 (HPV-16) E6/E7 genes. Human umbilical vein endothelial cells (HUVEC) primary cultures and the EAhy.926 cells (Cora-Jean S. Edgell, Ph.D., University of North Carolina), a line that was generated by fusing HUVEC with a carcinoma cell line [23], were maintained in EBM-2 media supplemented with 2\% FBS (Cambrex Bio Science). SHetA2 was synthesized by K. Darrell Berlin (Oklahoma State University) as previously described [14], dissolved in dimethyl sulfoxide (DMSO) at a concentration of $0.01 \mathrm{M}$ and stored at $-80^{\circ} \mathrm{C}$. All manipulations were performed in subdued lighting to avoid photo-oxidation of the drug. Recombinant Thymidine Phosphorylase (R\&D Systems) was dissolved in Phosphate Buffered Saline at a concentration of $10 \mu \mathrm{g} / \mathrm{mL}$.

Microarray analysis of organotypic cultures

Organotypic cultures of A2780 ovarian cancer cells were prepared as previously described [8]. Briefly, cells were plated inside and on top of collagen gels and allowed to grow suspended in a tissue culture insert with $8 \mu$ pores for 1 week to generate tissue-like architecture. A final concentration of $1 \mu \mathrm{M}$ SHetA2 or the same volume of solvent (DMSO) were then administered to nine replicate cultures for each treatment group. Media and drug were replenished on a schedule of every Monday, Wednesday and Friday for 2 weeks. One set of the treated and untreated cultures was fixed in formalin, embedded in paraffin. Five micron sections were stained with hematoxylin and eosin (H\&E) for histologic evaluation (S.L.). The remaining cultures were treated with $0.1 \%$ collagenase and the released cells were pelleted and frozen at $-80^{\circ} \mathrm{C}$.

RNA was isolated from four replicate frozen cell pellets each of untreated and treated cultures using the RNAeasy kit (Qiagen, Valencia CA) in combination with the Qiagen shredder. RNA was quantified by determining the optical density (OD) at 260 and $280 \mathrm{~nm}$ and all exhibited OD 260/280 ratios 1.9 or greater. The integrity of the RNA was confirmed by gel electrophoresis prior to use in microarray and rt-PCR analysis. The microarrays were printed at Microarray Research Facility of Oklahoma Medical Research Foundation from Human Genome Oligo Set Version 2.1 (QIAGEN Operon, Alameda, CA) according to manufacturer's instruction. This 70 -mers oligo set contains 21,329 oligonucleotides. The oligos were derived from the UniGene and RefSeq databases. The details of microarray slides preparation was described in Jarvis et al. (2004). Cy3-labeled cDNA molecules were synthesized from $10 \mu \mathrm{g}$ of RNA using CyScribe cDNA Post Labeling Kit (Amersham, Piscataway, NJ). cDNA was added to ChipHybe $^{\mathrm{TM}}$ hybridization buffer (Ventana Medical Systems, Tucson, AR) containing Cot-1 DNA $(0.5 \mathrm{mg} / \mathrm{mL}$ final concentration $)$, yeast tRNA $(0.2 \mathrm{mg} / \mathrm{mL})$, and poly $(\mathrm{dA})_{40-60}$ $(0.4 \mathrm{mg} / \mathrm{mL})$. Hybridization was performed on a Ventana Discovery system for $6 \mathrm{~h}$ at $42^{\circ} \mathrm{C}$. Microarrays were washed to a final stringency of $0.1 \times \mathrm{SSC}$, and then scanned using a dual-color laser instrument (Agilent Biotechnologies, Palo Alto, CA). Fluorescent intensity was measured by Imagene ${ }^{\mathrm{TM}}$ software (BioDiscovery, Marina del Rey, CA).

Data normalization and robust regression was conducted as described in Dozmorov and Centola [24]. Briefly in these two steps: (1) the first step was conducted to correct the nonspecific binding of background for individual slide. This procedure is based on the fact that spot intensities from genes not expressed by the samples of interest constitute noise and are therefore normally distributed. The mean $\left(S_{0}\right)$ and standard deviation $\left(\mathrm{SD}_{0}\right)$ of these non-expressed genes were calculated using an iterative nonlinear curve fitting procedure and used as background parameters for normalization using the formula $S^{\prime}=\left(S-S_{0}\right) / \mathrm{SD}_{0}$. After the first step, the normal distributed background signal for nonexpressed genes has a mean of 0 and standard deviation (SD) of 1 ; (2) The second step is then performed using genes significantly expressed above background ( $>3 \mathrm{SD}$ above background) to correct overall variations between slides using a robust regression procedure based on the observation that the expression levels 
of the majority of genes do not change in compared samples. From the normalized data, a "reference group" was then establish as previously described to provide a baseline estimate of the variance derived from technical variation and biological stochastic processes present among samples [25]. Only genes whose differences between treated and untreated samples above the differences present in the "reference group" were considered to be truly differentially expressed and used to select genes for validation.

Relative real time reverse transcriptase polymerase chain reaction

Monolayer cultures were treated with a range of SHetA2 concentrations or DMSO control for a range of treatment times. Cells were lysed in RNA isolation buffer and RNA isolated as described above was evaluated in triplicate reactions using validated TaqMan primers (Applied Biosystems) specific for the test TP, TSP-4, VEGF and bFGF genes and the control $18 \mathrm{~S}$ genes according to manufacturers instructions. The delta ct method was used to normalize the expression of each test gene to the housekeeping $18 \mathrm{~S}$ gene and to determine the relative expression of the test genes at each dosage or time point in comparison to the solvent only control cultures [26]. Experiments were repeated with RNA isolated from independent sets of treated cultures.

\section{Measurement of SHetA2 effects of VEGF, bFGF and growth}

The effects of a range of SHetA2 concentrations on growth and secretion of VEGF and bFGF in A2780 ovarian cancer cells and D1 normal endometrial cultures were evaluated in parallel. Cells were plated into 96-well plates in $50 \mu \mathrm{L} /$ well at a concentration of 1,000 cells/well and incubated overnight. The next day, $50 \mu \mathrm{L}$ of solutions containing $2 \mathrm{X}$ concentration of SHetA2 in growth media were added to the relevant wells to achieve the desired concentration range of 2, 4, 6, 8 and $10 \mu \mathrm{M}$ SHetA2 final concentrations in triplicate. The same final volume of DMSO achieved in these treatments was administered to the untreated controls. After $72 \mathrm{~h}$ of treatment, aliquots of the conditioned media were removed and immediately stored at $-80^{\circ} \mathrm{C}$ for VEGF$\mathrm{A}$ and bFGF measurements. The amount of cells remaining in each well was measured using the CellTiter 96 Aqueous One Solution Cell Proliferation Assay (Promega) to confirm that effectiveness of the drug in each experiment

Western blot analysis

Cell cultures were harvested with a cell scraper, washed once with PBS and pelleted by centrifugation. The M-PER
Mammalian Protein Extraction Reagent (Pierce) and protease inhibitor cocktail (Sigma) were used to extract proteins. Xenograft frozen samples were homogenized in RIPA buffer to extract proteins and cell debris was removed by centrifugation. Concentrations of the protein extracts were determined using PIERCE BCA protein assay kit. Proteins $(100 \mu \mathrm{g})$ were separated by $10 \%$ SDS-polyacrylamide gel, electroblotted onto nitrocellulose membranes and then blocked with $5 \%$ nonfat milk in $0.1 \%$ Tween 20 -TBS for $2 \mathrm{~h}$ at room temperature. The membranes were immunoblotted with an anti-TP goat polyclonal antibody. After further washing, the blots were incubated with donkey-antigoat secondary antibody. Antibody binding was detected with the Western Blotting Luminol Reagent (Santa Cruz Biotechnology). Membranes were stripped and re-probed with mouse polyclonal GAPDH or $\beta$-actin as protein loading controls. All antibodies used were purchased from Santa Cruz Biotechnology.

For measuring secreted TSP4, cells were plated at $2.5 \times$ $10^{5}$ per well in a six well plate. Media was changed after $24 \mathrm{~h}$ and cells were treated with SHetA2 for different time points. The media was collected at each time point and an equal volume of media was used for immunoprecipitation using TSP4 antibody (Santa Cruz Biotechnology) conjugated to protein $\mathrm{G}$ agarose. The immunoprecipitates were run on SDS-PAGE and analyzed by western blot analysis using TSP4 primary antibody (R\&D systems) following western blot protocol described above.

\section{VEGF and bFGF measurements}

Quantikine Human enzyme-linked immunosorbent assay (ELISA) kits for VEGF-A and bFGF (R\&D Systems) were used to quantify the concentration of VEGF or bFGF in conditioned media. Absorbance was measured using an automatic microplate reader at 450 and $540 \mathrm{~nm}$. The concentration of VEGF-A or bFGF in each sample was interpolated from the plate specific standard curve after subtracting the background staining at $540 \mathrm{~nm}$ from the absorbance measured at $450 \mathrm{~nm}$.

\section{Conditioned media}

For the conditioned media experiments, epithelial cells were plated at 400,000 cells per well of 6 well tissue culture dishes and cultured in the presence and absence of $10 \mu \mathrm{M}$ SHetA2 in McCoy's growth media for the kidney HK-2 normal and Caki-1 cancer and IOSE- 80 media for the ovarian epithelial IOSE- 80 normal and A2780 cancer cells. After $48 \mathrm{~h}, 1 \mathrm{~mL}$ aliquots were removed and centrifuged to remove cellular debris. The cleared media was immediately used or cryopreserved at $-80^{\circ} \mathrm{C}$. For the TP experiments, recombinant TP (R\&D Systems) was added (final concen- 
tration $125 \mathrm{mg} / \mathrm{mL}$ ) to half of the SHetA2 and half of the control solvent only wells. After another $24 \mathrm{~h}, 1 \mathrm{~mL}$ aliquots of media from the different indicated conditions were removed and centrifuged to remove cellular debris.

HUVEC endothelial tube formation assay

The endothelial tube formation assay was performed using the Chemicon in vitro Angiogenesis Assay Kit. Wells in a 96 well plate were coated with ice cold EC Matrix Gel Solution in the EC Matrix Diluent Buffer. After solidification of the matrix at room temperature, HUVEC cells were seeded onto the polymerized EC Matrix at a concentration of 10,000 cells in $50 \mu \mathrm{L}$ of EMB-2 media per well. Fifty microliters of conditioned media was immediately added after plating HUVEC cells for a final 1:1 ratio of EMB-2 media to conditioned media. The number of tubule branches were photographed and counted after $16 \mathrm{~h}$ of incubation. The results from three independent experiments performed in triplicate were averaged. To study direct effects of SHetA2 on endothelial tube formation, eight treatments were performed in duplicate. Four treatments consisted of $0,1,3$ or $5 \mu \mathrm{M}$ of SHetA2 while the remaining four received these treatments in addition to $125 \mathrm{mg} / \mathrm{mL}$ of TP. After $16 \mathrm{~h}$ incubation at $37^{\circ} \mathrm{C}$, photomicrographs were taken and the number of branch tubules were counted. The results of three experiments performed in duplicate were averaged.

\section{EAhy.926 endothelial tube formation assay}

The endothelial tube formation assays performed with EAhy.926 cells were performed using a slight modification of the method published by others [27, 28]. Ninety-six-well microtiter plates will be coated with $150 \mu \mathrm{L}$ Matrigel at $4^{\circ} \mathrm{C}$ and incubated for $30 \mathrm{~min}$ at $37^{\circ} \mathrm{C}$ to allow the gel to solidify. EAhy.962 were plated onto the Matrigel-coated wells at a concentration of 10,000 cells per well. The cultures were immediately treated with $0,1,5$ or $10 \mu \mathrm{M}$ SHetA2 or DMSO solvent control in triplicate in an arbitrary pattern and grown for $20 \mathrm{~h}$. The wells were evaluated under a microscope by a person blinded to the treatment order of the wells and who counted the number of tube branches. Photomicrographs were taken to record the characteristics of the cultures under various treatment conditions.

\section{Cell cycle analysis}

HUVECs were plated at $1 \times 10^{6}$ cells per plate and treated with SHetA2 at $0,1,3$ and $5 \mu \mathrm{M}$ in the absence or presence of $125 \mathrm{mg} / \mathrm{mL}$ TP. A parallel set of plates were treated with DMSO. After 16 and $24 \mathrm{~h}$ of incubation, the cells were washed with PBS, trypsinized and collected in cell culture medium. Cells were centrifuged, washed with PBS, and centrifuged again. The cell pellet was resuspended in $2 \mathrm{~mL}$ PBS and cells were fixed by drop-wise addition of $5 \mathrm{~mL}$ of $100 \%$ ethyl alcohol while vortexing. After incubation overnight at $4{ }^{\circ} \mathrm{C}$, the cells were centrifuged and washed in PBS, and pelleted again. The cells were resuspended in $1 \mathrm{~mL}$ of staining solution containing $5 \%$ TritonX-100, $1 \mathrm{mg} / \mathrm{mL}$ RNase and $1 \mathrm{mg} / \mathrm{mL}$ propidium iodide (PI) in phosphate buffered saline and allowed to stained for $3 \mathrm{~h}$ in the dark at room temperature. The samples were then analyzed using a FACSCalibur (Becton Dickinson) automated benchtop flow cytometer and quantified using Summit for MoFlo Acquisition and Sort Control Software (Cytomation).

\section{Apoptosis assay}

The Vybrant Apoptosis Assay Kit \#3 (Molecular Probes) was utilized to measure apoptosis and necrosis. Tissue culture medium in each well was collected to harvest cells that had already lifted off the tissue culture plate. These were combined with adherent cells that were harvested by trypsinization. The cells were pelleted by centrifugation and resuspended in $100 \mu \mathrm{L}$ of $1 \mathrm{X}$ annexin-binding buffer, and then incubated with $5 \mu \mathrm{L}$ of annexin $\mathrm{V}$ conjugated to fluorescein (annexin-V-FITC) and $1 \mu \mathrm{L}$ of $100 \mu \mathrm{g} / \mathrm{mL}$ PI dye for $15 \mathrm{~min}$ at room temperature. The solution was then mixed gently with an additional $400 \mu \mathrm{L}$ of $1 \mathrm{X}$ annexinbinding buffer and the samples were evaluated with Flow Cytometry at an excitation wavelength was $488 \mathrm{~nm}$ and observation wavelengths of 530 and $575 \mathrm{~nm}$.

\section{Xenograft tumors}

Caki-1 xenograft tumors were provided by Melinda Holingshead, $\mathrm{PhD}(\mathrm{NCI})$ from an experiment in which 25 tumor bearing mice were gavaged with polyethylene glycol (PEG400) and three groups of 15 tumor bearing mice each were gavaged with 20,40 and $60 \mathrm{mg} / \mathrm{kg} /$ day SHetA2 in PEG400. Significant effect on tumor size was observed only in the highest treatment group at $40 \%$ reduction in tumor size. Tumors were fixed in formalin and embedded in paraffin. Sections $(5 \mu)$ of tumor blocks were dewaxed in xylene, rehydrated in graded ethanol, and washed in water followed by TBS (50 mM Tris- $\mathrm{HCl}$ and $150 \mathrm{mM} \mathrm{NaCl}, \mathrm{pH}$ 7.4) and stained with hematoxylin and eosin (H\&E) and trichrome for histological evaluation. Immunohistochemical analysis of TP expression was performed using the TP/PDECGF Ab-1 primary antibody (Labvision) and the UltraStreptavidin Detection System HRP (Signet). After rinsing in distilled water, sections were counterstained with hematoxylin. 


\section{Results}

Microarray analysis of ovarian cancer organotypic cultures suggests anti-angiogenesis activity

The first indications that Flex-Het regulated expression of angiogenic cytokines were observed in microarray analysis. The biological model used consisted of A2780 ovarian cancer cells grown in organotypic culture for 2 weeks with a low dose of SHetA2 (1 $\mu \mathrm{M})$ or DMSO solvent control. Histological evaluation of the cultures demonstrated that both apoptosis and differentiation were induced in the treated cultures in comparison to the untreated controls exposed to solvent only (Fig. 1a). Most of the cell clumps in the treated cultures were undergoing apoptosis with some

a

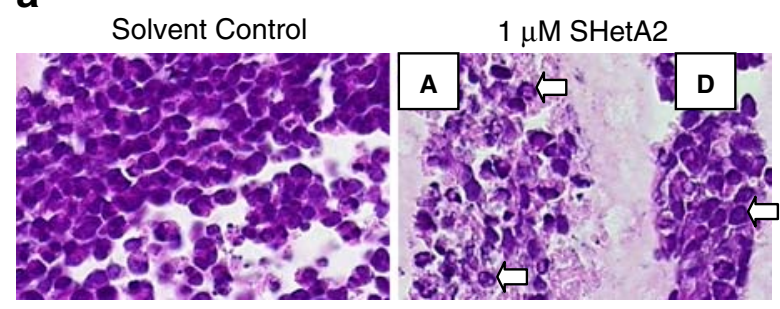

C

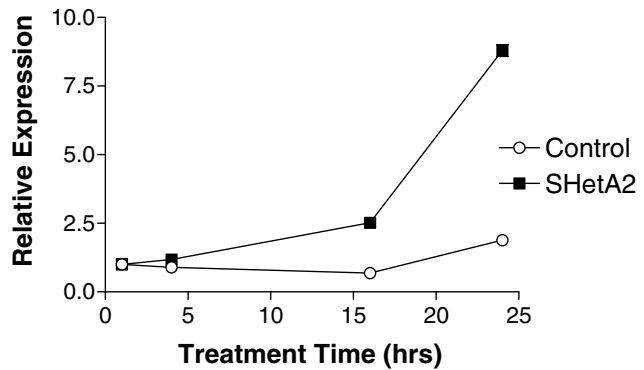

$\begin{array}{lllllll}\text { Time (hrs) } & 0 & 2 & 4 & 8 & 24 & 24 \mathrm{C}\end{array}$

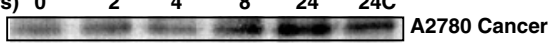

IOSE-80 Normal
Fig. 1 Differentiation and apoptosis in A2780 organotypic cultures used for microarrays (a). Twelve A2780 organotypic cultures were grown in the absence of drug. After 10 days of growth, six of the cultures were treated with $1 \mu \mathrm{M}$ SHetA2 and six were treated with the same volume of solvent. After 2 weeks of treatment with drug or solvent, one untreated and one treated culture were fixed in formalin, embedded in paraffin, sectioned and stained with hematoxylin and eosin (H\&E). Photomicrographs representative of the entire cultures are presented in this figure $(\times 40)$. The other collagen gels were digested with collagenase, the cells were pelleted, and the RNA was isolated for microarray and validation analysis. The arrows point to cells exhibiting nuclear characteristics of early apoptosis. A smaller fraction of the clumps in the treated cultures contained cells that exhibited more differentiated phenotypic characteristics. Microarray analysis of RNA isolated from these cultures identified a total of 44 genes that were differentially expressed between treated and untreated sample groups. Out of the 44 selected genes, 21 have known annotation information and are presented in Table 1. TP, which encodes a known angiogenic factor, was only expressed in untreated cells suggesting that repression of these gene by SHetA2 may lead to anti-angiogenic activity. SHetA2 repression of TSP-4 however, contradicted this theory, because it encodes an uncharacterized member for a family of TSP genes that encode anti-angiogenic proteins.

b
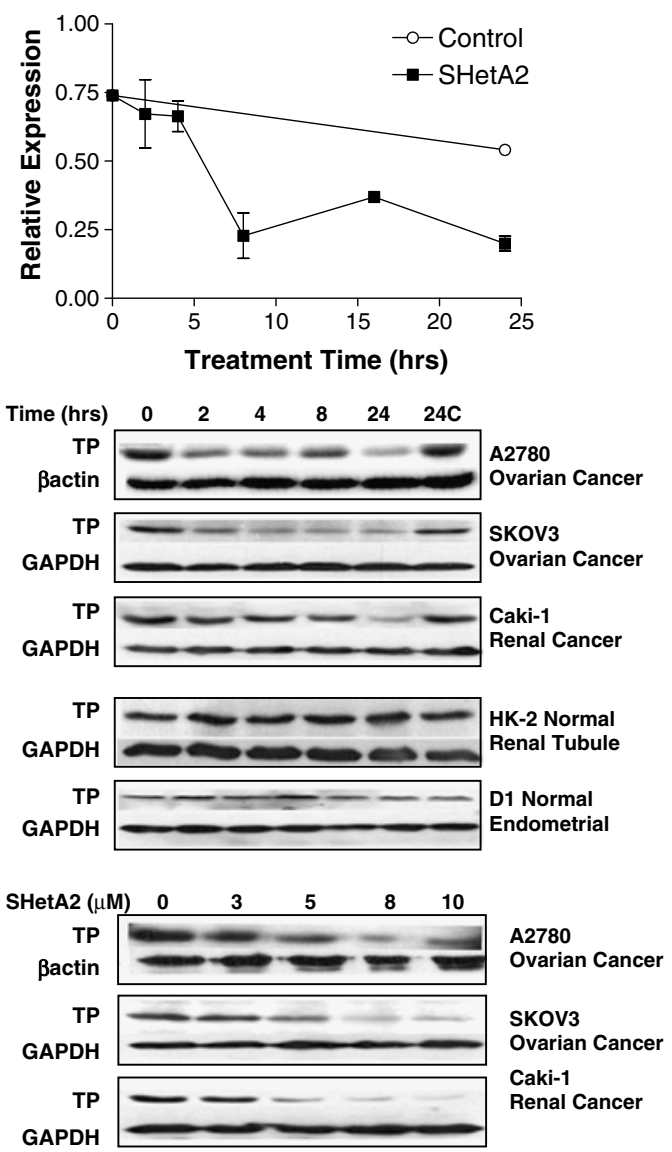

nuclei undergoing early apoptosis in both apoptotic clump $(A)$ and differentiating clump $(D)$. Regulation of TP (b) and TSP-4 (c) mRNA and protein expression. A2780, SK-OV-3, Caki-1, HK-2, and D1 cells were treated with the indicated doses of SHetA2 for $24 \mathrm{~h}$ or $10 \mu \mathrm{M}$ SHetA2 for the indicated amount of time. RNA extracts from A2780 cultures were evaluated using rt-PCR. Protein extracts from the indicated cell lines were evaluated by Western blot analysis for timeand dose-response effects on TP expression by SHetA2. TSP-4 was immunoprecipitated from conditioned media and evaluated by Western blot 
Table 1 Differentially expressed genes in organotypic ovarian cancer model of SHetA2-induced differentiation

\begin{tabular}{|c|c|c|c|c|c|c|c|c|c|c|}
\hline \multirow[t]{2}{*}{ Function/description } & \multirow[t]{2}{*}{ Gene ID } & \multicolumn{3}{|c|}{ Untreated } & \multicolumn{3}{|c|}{ Treated } & \multirow[t]{2}{*}{$T_{\mathrm{a}}$} & \multirow[t]{2}{*}{$T_{\mathrm{s}}$} & \multirow[t]{2}{*}{ Ratio } \\
\hline & & Ave & SD & $P$ & Ave & SD & $P$ & & & \\
\hline \multicolumn{11}{|l|}{ A1 Over expressed in treated } \\
\hline FEV protein & NM_017521 & 2.19 & 0.77 & $1.20 \mathrm{E}-08$ & 3.57 & 0.79 & $0.00 \mathrm{E}+00$ & $3.60 \mathrm{E}-02$ & $4.40 \mathrm{E}-06$ & 1.63 \\
\hline $\begin{array}{l}\text { Endothelial zinc finger protein } \\
\text { induced by tumor necrosis factor } a\end{array}$ & $\mathrm{BC} 014280$ & 1.84 & 0.8 & $4.40 \mathrm{E}-06$ & 3.14 & 0.13 & $0.00 \mathrm{E}+00$ & $4.90 \mathrm{E}-02$ & $0.00 \mathrm{E}+00$ & 1.7 \\
\hline \multicolumn{11}{|l|}{ A2 Over expressed in untreated } \\
\hline PRO0618 protein & NM_014133 & 5.45 & 1.12 & $0.00 \mathrm{E}+00$ & 3.62 & 0.71 & $0.00 \mathrm{E}+00$ & $2.90 \mathrm{E}-02$ & $3.30 \mathrm{E}-05$ & 0.66 \\
\hline Protease inhibitor 15 & NM_015886 & 5.16 & 1.15 & $0.00 \mathrm{E}+00$ & 3.35 & 0.72 & $0.00 \mathrm{E}+00$ & $3.30 \mathrm{E}-02$ & $1.30 \mathrm{E}-05$ & 0.65 \\
\hline CGI-89 protein & AL161962 & 4.95 & 1.11 & $0.00 \mathrm{E}+00$ & 3.24 & 0.62 & $0.00 \mathrm{E}+00$ & $2.80 \mathrm{E}-02$ & $2.60 \mathrm{E}-06$ & 0.65 \\
\hline Galactosamine ( $N$-acetyl)-6-sulfate sulfatase & NM_000512 & 4.85 & 1.28 & $3.60 \mathrm{E}-14$ & 2.52 & 0.41 & $0.00 \mathrm{E}+00$ & $9.50 \mathrm{E}-03$ & $3.80 \mathrm{E}-15$ & 0.52 \\
\hline Smcx homolog, X chromosome (mouse) & NM_004187 & 4.73 & 1.15 & $2.20 \mathrm{E}-16$ & 2.89 & 0.59 & $0.00 \mathrm{E}+00$ & $2.10 \mathrm{E}-02$ & $5.10 \mathrm{E}-07$ & 0.61 \\
\hline Thrombospondin 4 & NM_003248 & 4.69 & 1.46 & $1.60 \mathrm{E}-10$ & 2.73 & 0.55 & $0.00 E+00$ & $3.90 E-02$ & $2.90 \mathrm{E}-06$ & 0.58 \\
\hline $\begin{array}{l}\text { Protein phosphatase } 1 \text {, regulatory } \\
\text { (inhibitor) subunit } 12 \mathrm{C}\end{array}$ & NM_017607 & 4.44 & 0.95 & $0.00 \mathrm{E}+00$ & 2.6 & 0.55 & $0.00 \mathrm{E}+00$ & $1.30 \mathrm{E}-02$ & $3.10 \mathrm{E}-07$ & 0.59 \\
\hline Galactose-4-epimerase & NM_000403 & 3.41 & 0.76 & $0.00 \mathrm{E}+00$ & 2.24 & 0.43 & $0.00 \mathrm{E}+00$ & $3.50 \mathrm{E}-02$ & $5.10 \mathrm{E}-05$ & 0.66 \\
\hline Alpha-1-B glycoprotein & AK027222 & 3.18 & 0.75 & $0.00 \mathrm{E}+00$ & 1.78 & 0.34 & $0.00 \mathrm{E}+00$ & $9.50 \mathrm{E}-03$ & $4.80 \mathrm{E}-09$ & 0.56 \\
\hline $\begin{array}{l}\text { Procollagen-proline, 2-oxoglutarate } \\
\text { 4-dioxygenase (proline 4-hydroxylase), } \\
\text { alpha polypeptide II }\end{array}$ & NM_004199 & 2.73 & 1.17 & $3.30 \mathrm{E}-06$ & 1.34 & 0.25 & $0.00 \mathrm{E}+00$ & $2.90 \mathrm{E}-02$ & $1.30 \mathrm{E}-13$ & 0.49 \\
\hline $\begin{array}{l}\text { Dopachrome tautomerase (dopachrome } \\
\text { delta-isomerase, tyrosine-related protein 2) }\end{array}$ & AJ000503 & 2.6 & 0.71 & $3.00 \mathrm{E}-13$ & 1.61 & 0.36 & $0.00 \mathrm{E}+00$ & $3.10 \mathrm{E}-02$ & $4.40 \mathrm{E}-06$ & 0.62 \\
\hline \multicolumn{11}{|l|}{ A3 Only expressed in treated } \\
\hline Bol, boule-like (Drosophila) & NM_033030 & 1.25 & 0.81 & $1.90 \mathrm{E}-03$ & 2.92 & 1.16 & $5.10 \mathrm{E}-07$ & $3.90 \mathrm{E}-02$ & $8.50 \mathrm{E}-06$ & 2.33 \\
\hline DNA-binding transcriptional activator & NM_006316 & 1.18 & 0.62 & $1.60 \mathrm{E}-04$ & 2.81 & 0.89 & $2.90 \mathrm{E}-10$ & $1.90 \mathrm{E}-02$ & $6.40 \mathrm{E}-10$ & 2.38 \\
\hline \multicolumn{11}{|l|}{ A4 Only expressed in untreated } \\
\hline SM-11044 binding protein & NM_020123 & 5.25 & 1.93 & $5.30 \mathrm{E}-08$ & 1.99 & 1.48 & $7.00 \mathrm{E}-03$ & $4.00 \mathrm{E}-02$ & $4.80 \mathrm{E}-03$ & 0.38 \\
\hline Thymidine phosphorylase (TP) & NM_001953 & 1.71 & 0.61 & $2.60 \mathrm{E}-08$ & 0.72 & 0.48 & $3.00 E-03$ & $3.50 E-02$ & $2.30 \mathrm{E}-03$ & 0.42 \\
\hline Transglutaminase 4 (prostate) & NM_003241 & 1.49 & 0.4 & $5.60 \mathrm{E}-14$ & 0.35 & 0.7 & $3.20 \mathrm{E}-01$ & $2.80 \mathrm{E}-02$ & $3.80 \mathrm{E}-03$ & 0.24 \\
\hline $\begin{array}{l}\text { ARP1 actin-related protein } 1 \text { homolog B, } \\
\text { centractin beta (yeast) }\end{array}$ & NM_005735 & 1.2 & 0.46 & $1.70 \mathrm{E}-07$ & 0.11 & 0.22 & $3.20 \mathrm{E}-01$ & $1.90 \mathrm{E}-02$ & $1.30 \mathrm{E}-03$ & 0.09 \\
\hline M-phase phosphoprotein 6 & NM_005792 & 0.98 & 0.24 & $4.40 \mathrm{E}-16$ & 0.24 & 0.48 & $3.20 \mathrm{E}-01$ & $2.80 \mathrm{E}-02$ & $4.00 \mathrm{E}-03$ & 0.24 \\
\hline 3-Hydroxyisobutyrate dehydrogenase & AK025558 & 0.84 & 0.31 & $5.20 \mathrm{E}-08$ & 0 & 0 & $1.00 \mathrm{E}+00$ & $1.20 \mathrm{E}-05$ & $3.80 \mathrm{E}-41$ & 0 \\
\hline
\end{tabular}

$P$ is probability that the given gene expression is not distinguishable from background. Small $P$ values indicate that gene is distinctive from background, or in other words "expressed". $T_{\mathrm{a}}$ is a result of the associative $t$ test in which the replicated residuals for each gene of the experimental group are compared with the entire set of residuals from the reference group. The null hypothesis (H0) is tested and considered true if gene expression in the experimental group presented as replicated residuals (deviations from averaged control group profile) is associated with the highly representative (several hundreds members) normally distributed set of residuals of gene expressions in the reference group. The significance threshold was corrected to make the appearance of false positive determinations improbable. $T_{\mathrm{s}}$ is the result of the Student $t$ test for replicates

Regulation of angiogenic cytokine expression in cancer and normal cell cultures

rtPCR analysis of RNA isolated from A2780 cultures confirmed that SHetA2 reduced expression of TP mRNA in a time-dependent manner (Fig. 1b). Down-regulation of TP protein expression also was observed in A2780 and SKOV3 ovarian cancer cell lines and the Caki-1 renal cancer cell line in time-dependent (Fig. 1b) and dosedependent (Fig. 1b) manners by Western blot analysis. Consistent with the differential induction of apoptosis and upstream events observed for SHetA2 in cancer versus normal cells [15], TP was down-regulated in cancer cell lines, but not in normal cultures of kidney tubule epithelial cells (HK-2 cell line) or primary endometrial cultures (D1) over a 24-h treatment period (Fig. 1b). Although rtPCR analysis indicated that TP was not completely eliminated by $24 \mathrm{~h}$ of treatment, the trend towards decreasing TP protein expression observed with time could lead to the lack of expression after 2 weeks of treatment as observed in the microarray analysis.

In contrast to the microarray results identifying TSP-4 down regulation by SHetA2, rtPCR demonstrated that TSP4 mRNA was up-regulated by SHetA2 in a time dependent manner (Fig. 1c). This up-regulation was confirmed by Western blot analysis of immunoprecipitated protein from 
conditioned media collected from SHetA2-treated and control cultures of ovarian cancer (A2780 cell line) and normal immortalized ovarian cancer cells (IOSE-80) in time-dependent manners (Fig. 1c). If TSP-4 possesses antiangiogenic activity similar to other members of the TSP family, this up-regulation would be consistent with SHetA2 exerting anti-angiogenesis activity. The differences observed in microarray and rtPCR results may be due to the different culture formats and incubation times evaluated. While microarray analysis is used in screening studies to identify genes involved in biological activities, the high level of artifact in this experimental format requires validation of the results. Since rtPCR is a more accurate technology considered as the gold standard for validation of microarray results, and Western blot analysis confirmed upregulation of TSP-4, it is therefore concluded that TSP-4 expression is increased by SHetA2 treatment.

Evaluation of the effects of SHetA2 on secretion of angiogenic and anti-angiogenic factors was expanded to include the well-characterized basic fibroblast growth factor (bFGF) and vascular endothelial growth factor (VEGF). rtPCR analysis demonstrated induction of bFGF mRNA expression in the A2780 ovarian cancer cell line (Fig. 2a). Evaluation of altered gene expression also needed to be evaluated at the cytokine secretion level, because altered
mRNA expression does not always translate linearly with altered protein secretion from cells due to multiple regulatory steps at the mRNA stability, translational, post-translational and secretion levels. SHetA2 induction of secretion of bFGF protein secretion was demonstrated by ELISA analysis of conditioned media collected from A2780 cultures (Fig. 2a). This up-regulation however was only observed at concentrations greater than $5 \mu \mathrm{M}$, while microarray and angiogenesis experiments presented below were all conducted at concentrations below $5 \mu \mathrm{M}$ to avoid induction of apoptosis that that occurs at higher concentrations.

Although SHetA2 induction of VEGF mRNA expression was observed in the A2780 cell line by rtPCR, ELISA of conditioned media demonstrated reduced levels of VEGF secretion after $8 \mathrm{~h}$ of SHetA2 treatment (Fig. 2b). To determine if inhibition of VEGF secretion was cell line specific, a series of cancer and normal cultures were evaluated. ELISA of conditioned media demonstrated higher levels of VEGF secretion in the cancer cultures (A2780 ovarian and Caki-1 renal cancer cell lines) in comparison to the normal cultures (HK-2 normal renal tubule and D1 primary endometrial cultures). Dose-responsive inhibition of VEGF secretion was exerted by SHetA2 in all cell types evaluated (Fig. 2b) consistent with the proposed anti-angiogenic activity.

a
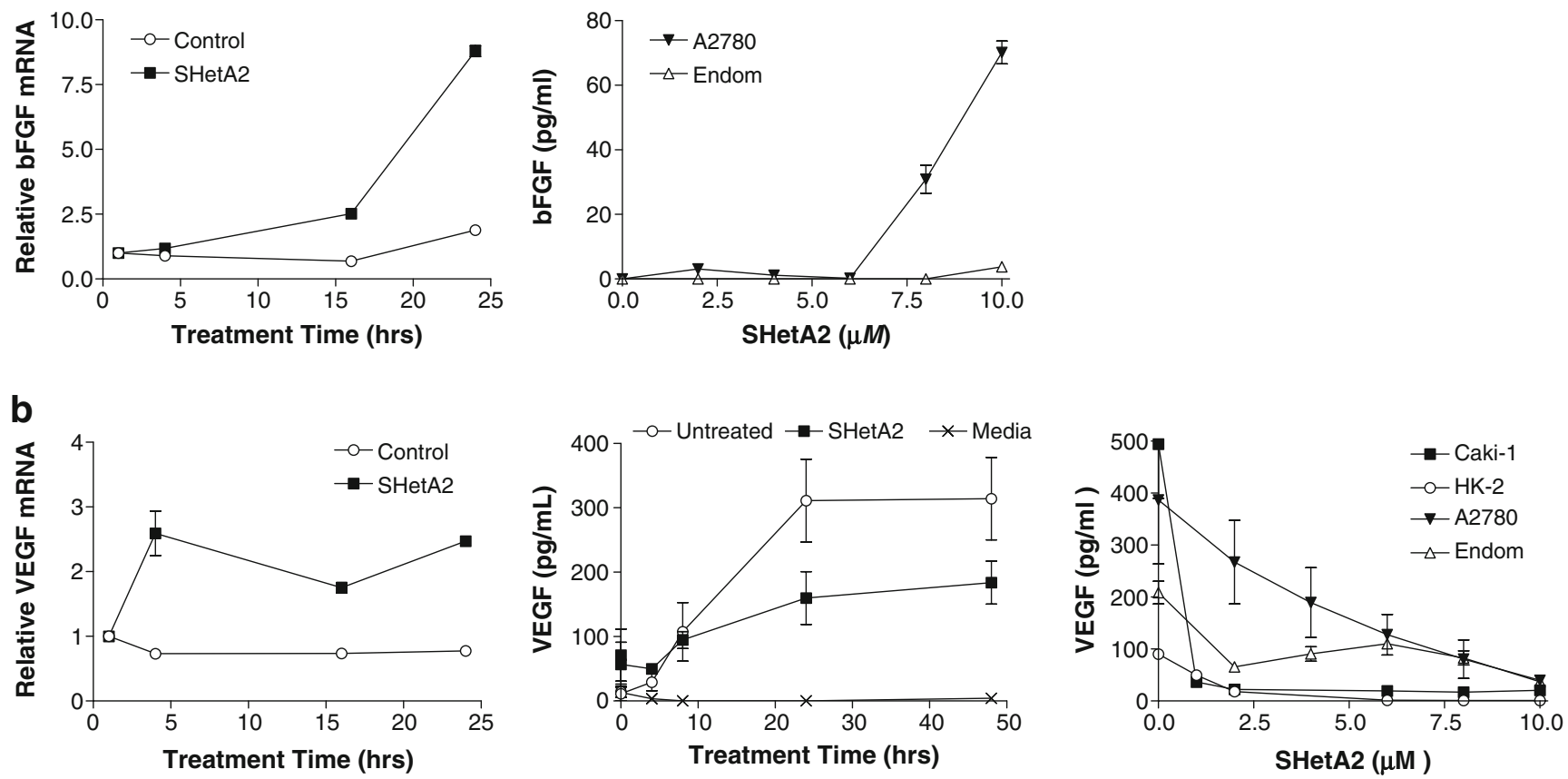

Fig. 2 Regulation of bFGF and VEGF mRNA and protein expression. RNA isolated from A2780 cultures treated with $10 \mu \mathrm{M}$ SHetA2 or solvent for the indicated time was analyzed by rt-PCR for bFGF (a) and VEGF (b) expression. Results or rtPCR experiments presented are representative of two independent experiments performed in triplicate.
Media conditioned by incubation with A2780 cultures and other indicated cultures were evaluated for bFGF (a) or VEGF (b) protein secretion by ELISA. ELISA results are averages of three independent experiments performed in triplicate 
Differential secretion of angiogenic cytokines from cancer versus normal cells

Before Flex-Het effects on secretion of angiogenic factors from cells could be evaluated, an experimental model with multiple levels of control was needed. The approach involved conditioning media by incubation with cultured cells for $48 \mathrm{~h}$. Angiogenic activity of cell secretions that accumulated in the conditioned media was quantified in the endothelial tube formation assay. In this assay, endothelial cells plated on Matrigel were cultured in a 1:1 mixture of the endothelial cell growth media to the conditioned media. The number of endothelial tube branches that formed after $16 \mathrm{~h}$ of incubation of triplicate cultures were counted and compared between different treatments (Fig. 3a-c). The majority of angiogenic factors present in the media containing FBS were degraded upon incubation at $37^{\circ} \mathrm{C}$ for $48 \mathrm{~h}$ as demonstrated by the number of endothelial tube branches formed in cultures exposed to media that was freshly removed from $4^{\circ} \mathrm{C}$ storage in comparison to
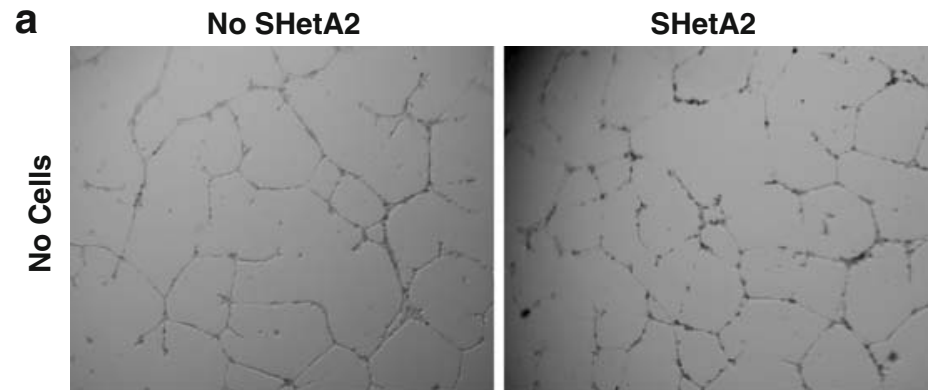

b
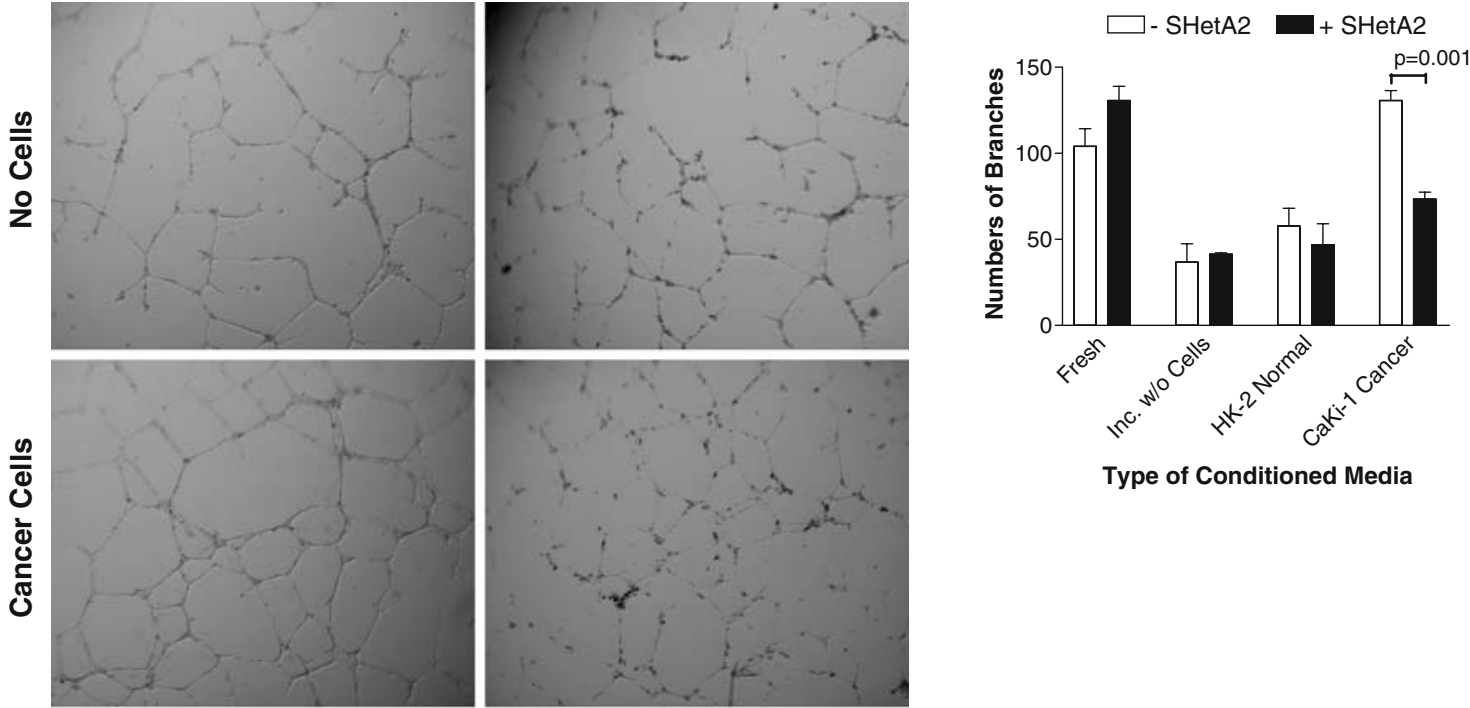

Type of Conditioned Media
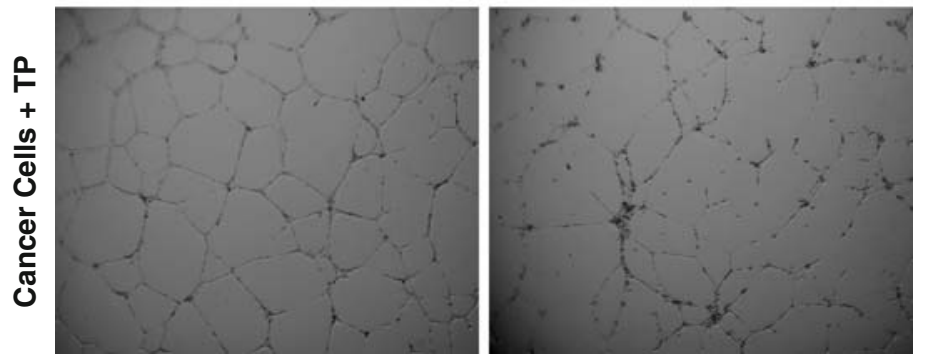

C
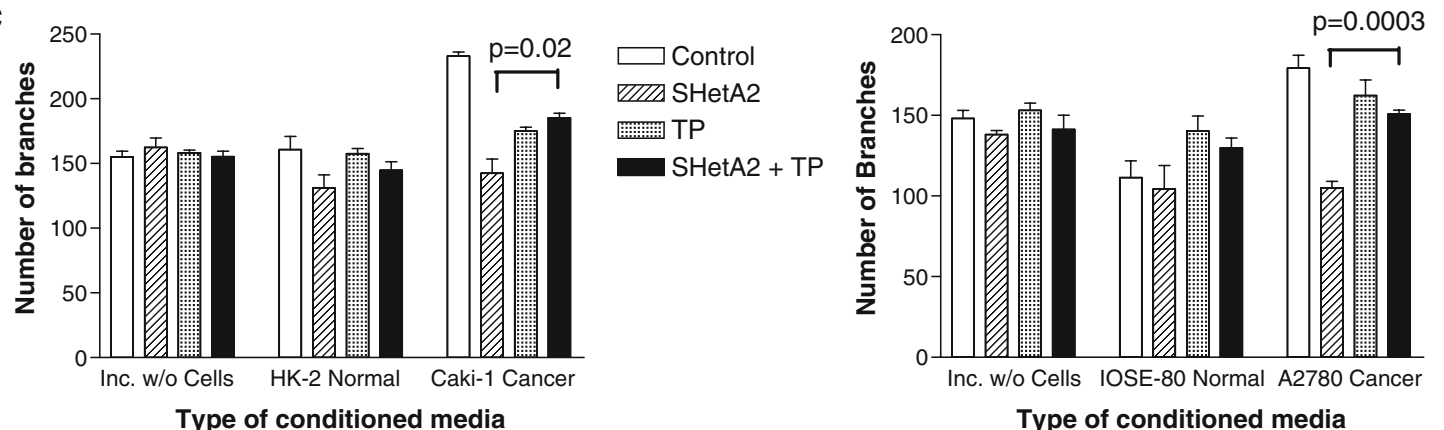

Fig. 3 Regulation of angiogenic factor secretion from epithelial cultures. The effects of the indicated types of conditioned media on endothelial tube branches are documented by photomicrographs (a) and quantification of endothelial branches (b and $\mathbf{c})$. The results from

three independent experiments performed in triplicate were averaged. Significant differences with $P$ values $<0.05$ were determined by a twotailed $t$ test in $\mathbf{b}$ and by ANOVA in $\mathbf{c}$ 
media that had been incubated without cells (compare "Fresh" with "Inc. w/o Cells" in Fig. 3b). Incubation of the media with Caki-1 renal cancer cells however generated conditioned media that had similar angiogenic activity to the fresh media (Fig. 3b). Conditioned media from HK-2 normal cell cultures did not exert angiogenesis activity (Fig. 3b). A similar pattern of angiogenesis activity secretion from cancer and not normal cultures was observed when A2780 ovarian cancer cells and IOSE80 ovarian normal cells were compared (Fig. 3c). To avoid artifacts caused by different media formulations, identical media was used for each set of cancer and control cultures: McCoy's growth media for Caki-1 cancer and HK-2 normal kidney cultures, and IOSE- 80 growth media for A2780 cancer and IOSE-80 normal ovarian epithelial cultures.

SHetA2 inhibition of secretion of angiogenic cytokines and promoting activity

In evaluating the effects of SHetA2 on secretion of angiogenic factors from the epithelial cultures it is important to control for potential direct effects on endothelial cells by residual SHetA2 drug remaining in the media after conditioning. Therefore, conditioned media were compared to media that were incubated with the same drug and time frame in the absence of cells. Comparison of the -SHetA2 and + SHetA2 bars Fig. 3b, demonstrates that the residual SHetA2 remaining in the media incubated without cells had no effect on the number of branches formed. The ability of Caki-1 cancer cells to restore incubated media to the level of angiogenesis activity exhibited by fresh media that was observed in Fig. 3b, was significantly reduced by SHetA2 treatment (Fig. 3b; two-tailed $t$ test $P=0.001$ ). This inhibitory activity of SHetA2 on angiogenic cytokine secretion from cancer cells could be counteracted by replenishing the media with exogenous recombinant TP for both renal and ovarian cancer cells (Fig. 3c). VEGF could not be evaluated in this manner because it is an essential component of the endothelial tube formation assay.

Direct action of Flex-Het on endothelial cell tubule formation

The ability of SHetA2 to directly affect HUVEC cells and immortalized endothelial Eahy.923 cells was evaluated in the endothelial tube formation assay. A dose-responsive inhibition of endothelial vascular tube branching was caused in both cell types by SHetA2 treatment (Fig. 4a,b). The EAhy.926 cells formed thicker tubules, possibly due to the fused carcinoma component of this cell line (Fig. 4a). SHetA2-treated EAhy.926 tubules developed increased thickness at $1 \mu \mathrm{M}$ and increasing proportions of solitary clumps of cells at 5 and $10 \mu \mathrm{M}$ indicated that SHetA2 may be inhibiting endothelial cell migration. Although addition of exogenous recombinant TP to the culture media slightly decreased tubule branching in the absence of SHetA2, recombinant TP treatment was able to attenuate the SHetA2 inhibition of endothelial tubule branching (Fig. 4b).

Induction of endothelial cell G1 phase cell cycle arrest, but not apoptosis

Since SHetA2 is known to induce cell cycle arrest at concentrations below $5 \mu \mathrm{M}$ and apoptosis at concentrations above $3 \mu \mathrm{M}$, HUVEC cells were evaluated with flow cytometry for cell cycle and apoptosis response to SHetA2 treatment. SHetA2 at concentrations ranging from 1 to $5 \mu \mathrm{M}$ induced $\mathrm{G} 1$ cell cycle arrest after $16 \mathrm{~h}$ (data not shown) and $24 \mathrm{~h}$ of treatment (Fig. 4c). The G1 arrest could not be prevented by exogenous recombinant TP treatment, suggesting that inhibition of TP is not involved in the mechanism of cell cycle arrest (Fig. 4c). Early apoptosis was not induced by 1 to $5 \mu \mathrm{M}$ SHetA2 in HUVEC cells, but necrosis (which cannot be differentiated from late apoptosis in this assay) appeared to be induced slightly at $5 \mu \mathrm{M}$ (Fig. 4d). Exogenous TP did not regulate apoptosis in the absence or presence of SHetA2 (Fig. 4d). There were no statistically significant differences between the numbers of live, early apoptosis or late apoptosis/early necrosis in the different treatment groups, as evaluated by ANOVA or by two-tailed $t$ tests.

\section{Regulation of angiogenic cytokines in HUVEC cells}

rtPCR analysis revealed a time-dependent induction of TP mRNA after $8 \mathrm{~h}$ of treatment with $5 \mu \mathrm{M}$ SHetA2 (Fig. 5a). Late upregulation of TP protein expression was confirmed by Western blot analysis after $24 \mathrm{~h}$ (Fig. 5b). A gradual increase of VEGF mRNA was consistent with increased VEGF protein secretion (Fig. 5c,d). The bFGF cytokine was unaltered by SHetA2 treatment of HUVEC cultures (Fig. 5d).

Inhibition of angiogenesis in vivo

Potential SHetA2 anti-angiogenesis activity in vivo was evaluated in H\&E stained sections of Caki-1 xenografts from an animal model conducted by the NCI RAID program in which $40 \%$ reduction of xenograft tumor size was induced by SHetA2 (Fig. 6a). Pathology review of the H\&E stained sections revealed that the carcinoma was invading the venous system and causing massive backup of blood and necrosis that is hemorrhagic. Figure 6a right hand panel shows a dilated blood vessel in the midst of a 
a Untreated Control

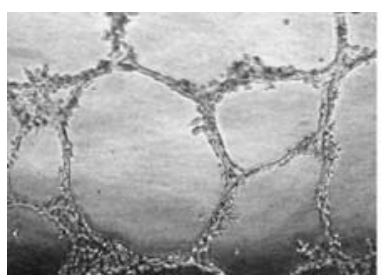

$5 \mu \mathrm{M}$ SHetA2

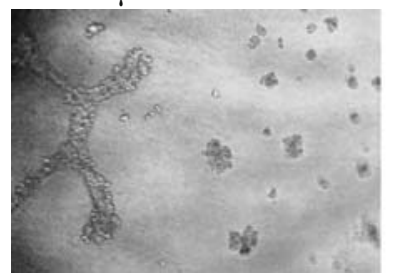

b

b
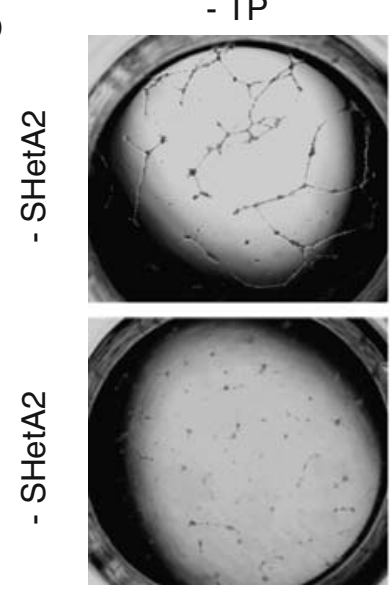

C

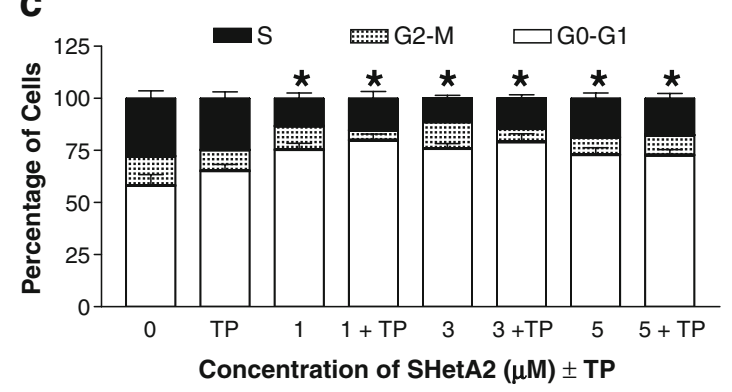

Fig. 4 Direct regulation of endothelial tube branching. Photomicrographs and quantification of branches in Eahy.926 cultures plated on Matrigel and treated with the indicated concentrations of SHetA2 (a). Photomicrographs and quantification of branches in HUVEC cultures plated on Matrigel and treated with the indicated concentrations of SHetA2 in the presence and absence of $125 \mathrm{mg} / \mathrm{mL}$ TP (b). Each

large area of necrosis. The SHetA2-treated tumors exhibited an ischemic type necrosis with little or no blood, which is known to occur when the blood supply is interrupted. Trichrome stain was used for better visualization of tumor vessels (Fig. 6b). The untreated tumors demonstrated a certain degree of vascular organization where blood vessels penetrate the tumor from the edge and go toward the center.
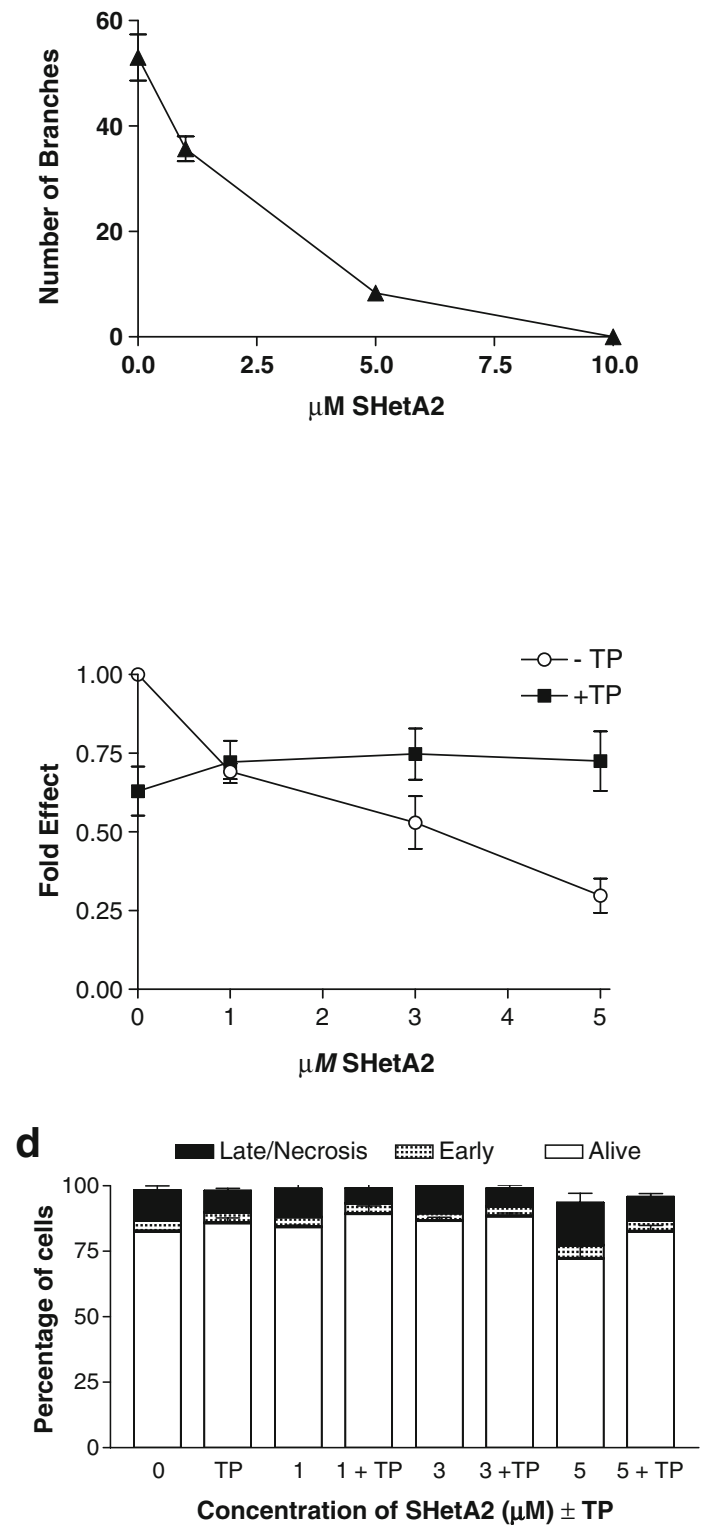

endothelial tube formation graph represents the average and standard error of four independent experiments performed in triplicate. Cell cycle (c) and apoptosis (d) profiles of HUVEC cultures treated with solvent or the indicated micromolar concentrations of SHetA2 in the presence and absence of $125 \mathrm{mg} / \mathrm{mL} \mathrm{TP}$ as determined by flow cytometric analysis

In general, smaller blood vessels extended from larger vessels and travel parallel to the tumor surface. In contrast, SHetA2 treated tumors show marked vascular disorganization. There was a greater amount of necrosis in areas not nourished by vessels and many necrotic areas that have blood vessels running through. TP staining of the Caki-1 xenograft sections demonstrated an increased expression 
a

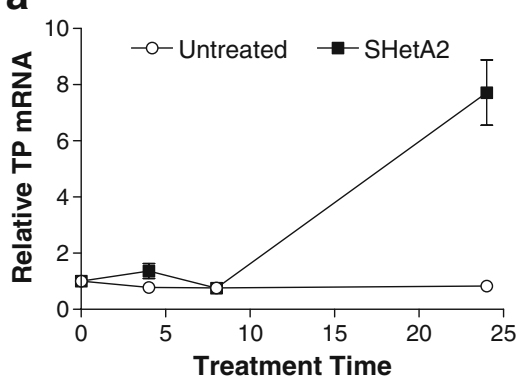

C

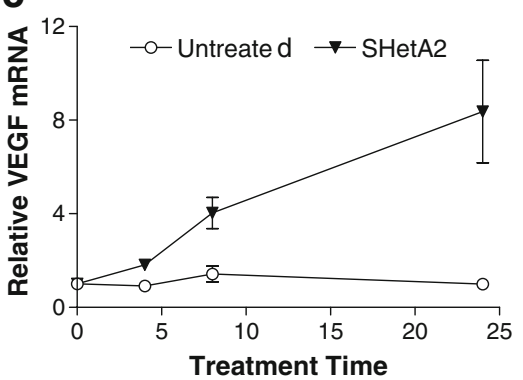

Fig. 5 Regulation of angiogenic cytokines in HUVEC cultures. HUVEC cultures were treated with $5 \mu \mathrm{M}$ or the indicated doses of SHetA2 for $24 \mathrm{~h}$. RNA isolated from the cultures was evaluated for expression of TP (a) and VEGF (c) mRNA using rt-PCR. Results represent the average and standard error of three independent experiments performed in triplicate. Protein extracts were evaluated by Western blot analysis for TP expression (b). Western blot results

of TP protein in all of the treatment groups (Fig. 6c). This was confirmed by Western blot analysis of tumor extracts (Fig. 6d).

\section{Discussion}

The results of this study demonstrate that the lead Flex-Het, SHetA2 exerts anti-angiogenic activity at multiple levels. Intracellular communication through secretion of cytokines represents the primary mechanism by which tumors recruit developing blood vessels. The inhibition of secretion of angiogenesis activity from cancer cell cultures by SHetA2 appears to be due to effects on several specific cytokines. The SHetA2 down-regulation of TP mRNA and protein was found to occur in cancer, but not normal cells and therefore may be related to the mechanism of differential induction of apoptosis. TP-catalyzed nucleotide salvage is an essential component of cellular and mitochondrial DNA replication and cell survival. TP and the 2-deoxy-D-ribose metabolite can inhibit intrinsic mitochondrial-driven apoptosis induced by hypoxia [19]. Therefore, the TP reduction by SHetA2 may be involved in the mechanism by which this drug induced the intrinsic mitochondrial apoptosis pathway $[11,15]$. Although angiogenesis effects of TSP-4 have not yet been characterized, the presence of type III

\section{b}
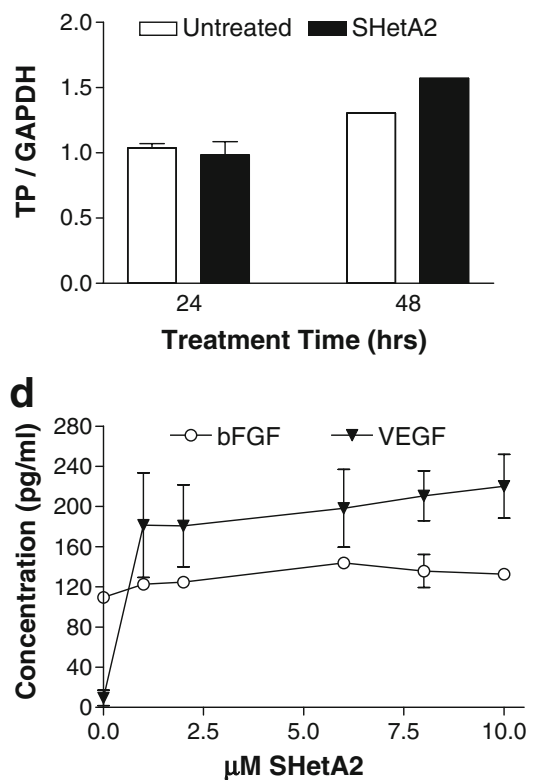

represent the average and standard error of two independent experiments. Data from one experiment was multiplied by a factor of 2 to normalize the results to the second experiment for presentation on a single graph. Conditioned media was evaluated by ELISA for VEGF expression (d). ELISA results represent the average and standard error of three independent experiments performed in triplicate

repeats, similar to the anti-angiogenic modules present in TSP-1 [22], suggests that TSP-4 is likely to be antiangiogenic. Thus, SHetA2 up-regulation of TSP-4 mRNA and protein secretion is consistent anti-angiogenic activity. Although VEGF mRNA was induced twofold, by SHetA2, the ultimate outcome of treatment across all normal and cancer cell lines tested was an inhibition of VEGF protein secretion, consistent with anti-angiogenic activity. The SHetA2 up-regulation of bFGF may not be severely interfering with the net anti-angiogenic effect because it is not up-regulated until after hours of treatment and only at high concentrations that can only be briefly achieved in vivo [29].

The process of developing and maintaining tumor blood vessels is controlled by a balance of pro- and antiangiogenic factors. Our hypothesis that the net effect of SHetA2 on this balance would be to reduce angiogenesis activity secreted from cancer cells was supported by SHetA2 reduction of angiogenesis stimulating activity in conditioned media from cancer cells. The role of TP in this net effect was supported by the partial reversal of this reduction upon addition of exogenous recombinant TP. Since TP has no known transcriptional regulatory activities, but plays a critical role in mitochondrial function [30], the mechanism by which TP attenuates SHetA2 reduction of angiogenic secretion is most likely through interference 
a
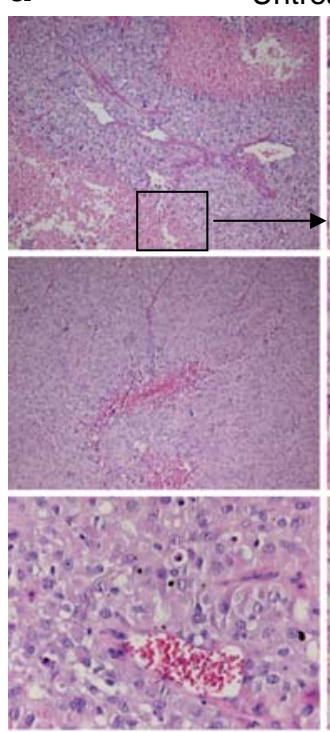

$60 \mathrm{mg} / \mathrm{kg} /$ day SHetA2
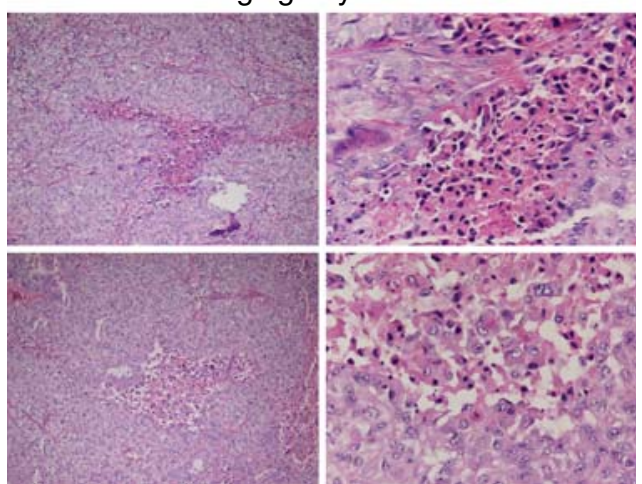

Fig. 6 In vivo regulation of angiogenesis in Caki-1 xenograft tumors. H\&E stained sections (a) demonstrate hemorrhagic necrosis in tumors for the untreated control group and ischemic necrosis in the tumors from the group gavaged with $60 \mathrm{mg} / \mathrm{kg} /$ day SHetA2. The photographs of untreated tumors show the carcinoma invading the venous system and causing massive backup of blood and necrosis that is hemorrhagic. The last photo of this panel shows a dilated blood vessel in the midst of a large area of necrosis. The photographs of the treated tumors show an ischemic type necrosis with little or no blood. This is caused by the blood supply being interrupted and occurs almost totally in the treated animals. Trichrome staining in of the sections (b) shows blockage and increased disorganization of blood vessels in the treated tumors in

with SHetA2 mitochondrial alterations [15]. SHetA2 regulation of the cytokines at the mRNA level, suggest that this drug may exert activities through transcriptional regulation. Preliminary data indicate that SHetA2 regulates gene expression through the nuclear factor kappa B (NF-K) transcription factor pathway [31,32].

The hypothesized direct effect of SHetA2 on endothelial cells was supported by the dose-dependent inhibition of endothelial tube formation in an in vitro assay. While the induction of G1 cell cycle arrest by SHetA2 on endothelial cells is likely to contribute to the mechanism of action inhibiting endothelial tube formation, it is not likely to be
C
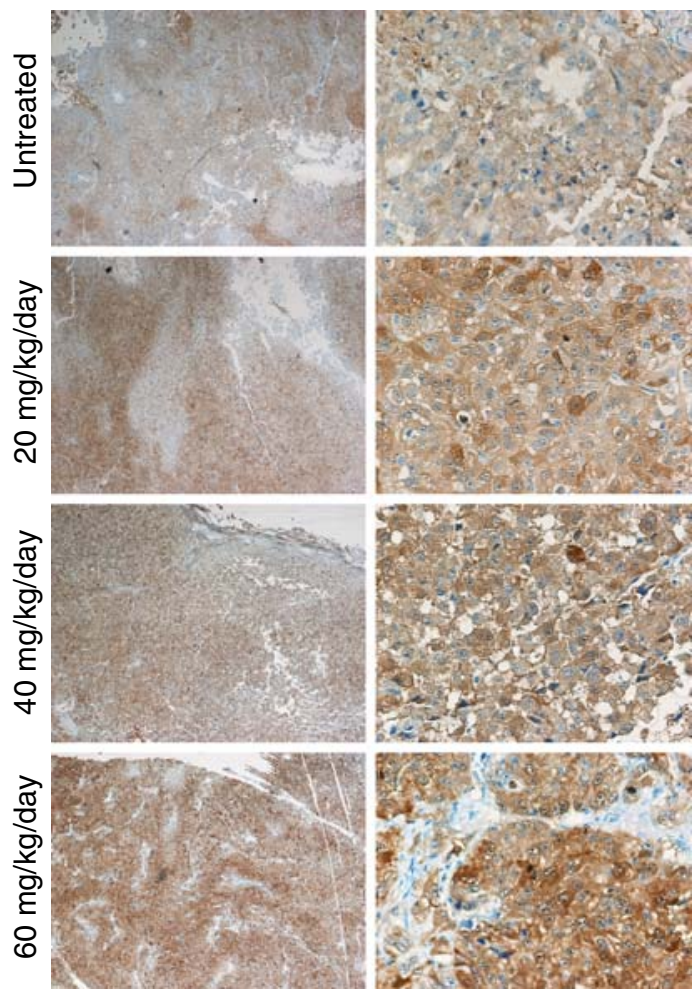

d

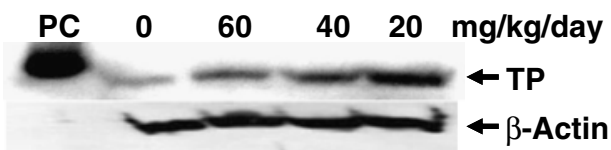

comparison to the controls. In untreated tumors, there is a certain degree of vascular organization where blood vessels penetrate the tumor from the edge and go toward the center. In general, smaller blood vessels extend from larger vessels and travel parallel to the tumor surface. In SHetA2 treated tumors show marked vascular disorganization. There is a greater amount of necrosis in areas not nourished by vessels and many necrotic areas that have blood vessels running through. Immunohistochemical analysis of TP expression (c) documents up-regulation of TP expression at the end of the 30-day treatment period. Western blot analysis of protein extracts taken from the tumors (d) confirms the TP upregulation

primarily responsible. This is because the G1 cell cycle arrest was not prevented by exogenous TP, while the endothelial tube formation was counteracted by TP. Also, the G1 arrest is induced in both cancer and normal cultures by SHetA2, while regulation of apoptosis and TP expression by SHetA2 occurs with a strong differential effect on cancer cells over normal cells. Necrosis or apoptosis are not likely to contribute to the mechanism by which SHetA2 inhibits endothelial tubule formation because only at concentrations above that used in the tubule assay are able to induce a slight increase in necrosis/apoptosis in endothelial cells. 
The induction of TP expression in endothelial cells is in contrast to the down-regulation of this protein in multiple cancer cell lines. Increased TP mRNA is not observed in endothelial cells within the first $8 \mathrm{~h}$ of treatment indicating that it is a late responding event. The ultimate outcome on endothelial tube formation however is inhibition, and the endothelial attempt to counteract this inhibition by increased TP expression does not appear to be able to counteract SHetA2 effects in vitro or in vivo.

SHetA2 inhibition of angiogenesis in vivo was confirmed in histologic evaluation of Caki-1 renal cancer xenografts. The $40 \%$ reduction in tumor size induced by SHetA2 in this animal model (Liu et al. 2008, in preparation) was associated with alterations in blood vessels. Necrosis occurred in tumors from both untreated control and SHetA2-treated animals. The type of necrosis in the untreated controls was associated with tumor cell invasion of blood vessels causing hemorrhage, while the type of necrosis that occurred in the tumors from treated animals was associated ischemia apparently due to lack of oxygen. This hypoxia appeared to be due to interference of the blood supply through blockage of the blood vessels causing swelling of the vessels and necrosis of the tumor cells within a short distance of the blood vessels. The dosedependent up-regulation of TP in the tumors was confirmed by Western blot analysis. A time-dependent experiment is planned to test the hypothesis that this up-regulation is a late response to hypoxia induced by SHetA2 inhibition of angiogenesis.

The results of this study demonstrated in vitro and in vivo anti-angiogenesis activity of SHetA2 through reduction of cancer cell secretion of angiogenic activity and through direct effects on endothelial cells. Reduction of the pro-angiogenic cytokines, TP and VEGF, and induction of the potential anti-angiogenic cytokine TSP-4, appear to be involved in the mechanism. The response of endothelial cells to SHetA2 anti-angiogenesis appears to involve upregulation of TP expression in vitro and in vivo. The complexity of angiogenesis regulation by SHetA2-induced alterations in the balance of pro- and anti-angiogenic factors will require a systems biology approach to provide sufficient understanding of the angiogenesis regulation to appropriately design planned clinical trials.

Acknowledgements We thank Patience Masamha, M.S. for her training and assistance with cell cycle analysis and Jim Henthorn (Director of the Flowand Image Cytometry Laboratory at the University of Oklahoma Health Sciences Center) for the training and advice. Grant support: NCI R01 CA106713.

Open Access This article is distributed under the terms of the Creative Commons Attribution Noncommercial License which permits any noncommercial use, distribution, and reproduction in any medium, provided the original author(s) and source are credited.

\section{References}

1. Amato RJ (2000) Chemotherapy for renal cell carcinoma. Semin Oncol 27:177-186

2. Rosa DD, Clamp AR, Collinson F, Jayson GC (2007) Antiangiogenic therapy for ovarian cancer. Curr Opin Oncol 19:497-505 doi:10.1097/CCO.0b013e32827035f0

3. Rini BI, Campbell SC, Rathmell WK (2006) Renal cell carcinoma. Curr Opin Oncol 18:289-296 doi:10.1097/01. cco.0000219260.60714.c4

4. Kerbel RS (2008) Tumor angiogenesis. N Engl J Med 358:20392049 doi:10.1056/NEJMra0706596

5. Grant DS, Williams TL, Zahaczewsky M, Dicker AP (2003) Comparison of antiangiogenic activities using paclitaxel (taxol) and docetaxel (taxotere). Int J Cancer 104:121-129 doi:10.1002/ ijc. 10907

6. Benbrook DM, Madler MM, Spruce LW, Birckbichler PJ, Nelson EC, Subramanian S et al (1997) Biologically active heteroarotinoids exhibit anticancer activity and decreased toxicity. J Med Chem 40:3567-3583 doi:10.1021/jm970196m

7. Zacheis D, Dhar A, Lu S, Madler MM, Klucik J, Brown CW et al (1999) Heteroarotinoids inhibit the growth of head and neck cancer cell lines in vitro and in vivo through both RAR and RXR retinoic acid receptors. J Med Chem 42:4434-4445 doi:10.1021/ jm990292i

8. Guruswamy S, Lightfoot S, Gold M, Hassan R, Berlin KD, Ivey RT et al (2001) Effects of retinoids on cancerous phenotype and apoptosis in organotypic culture of ovarian carcinoma. J Natl Cancer Inst 93:516-525 doi:10.1093/jnci/93.7.516

9. Dhar A, Liu S, Klucik J, Berlin KD, Madler MM, Lu S et al (1999) Synthesis and structure-activity relationships of nitrogen heteroarotinoids. J Med Chem 42:3602-3614 doi:10.1021/ jm9900974

10. Benbrook DM, Subramanian S, Gale JB, Liu S, Brown CW, Boehm MF et al (1998) Synthesis and characterization of heteroarotinoids demonstrate structure specificity relationships. J Med Chem 41:3753-3757 doi:10.1021/jm980308p

11. Chun K-H, Benbrook DM, Berlin KD, Hong WK, Lotan R (2003) Induction of apoptosis in head and neck squamous cell carcinoma (HNSCC) cell lines by heteroarotinoids through a mitochondrial dependent pathway. Cancer Res 63:3826-3832

12. Benbrook DM, Kamelle SA, Guruswamy SB, Lightfoot SA, Hannafon B, Rutledge TL et al (2005) Flexible heteroarotinoids (Flex-Hets) exhibit improved therapeutic ratios as anti-cancer agents over retinoic acid receptor antagonists. Invest New Drugs 23:417-428 doi:10.1007/s10637-005-2901-5

13. Mic FA, Molotkov A, Benbrook DM, Duester G (2003) Retinoid activation of RAR but not RXR is sufficient for mouse embryonic development. Proc Natl Acad Sci U S A 100:7135-7140 doi:10.1073/ pnas. 1231422100

14. Liu S, Brown CW, Berlin KD, Dhar A, Guruswamy SB, Brown D et al (2004) Synthesis of flexible sulfur-containing heteroarotinoids that induce apoptosis and reactive oxygen species with discrimination between malignant and benign cells. J Med Chem 47:999-1007 doi:10.1021/jm030346v

15. Liu T-Z, Hannafon B, Gill L, Kelly B, Benbrook DM (2007) FlexHets differentially induce apoptosis in cancer over normal cells by directly targeting mitochondria. Mol Cancer Ther 6:1814-1822 doi:10.1158/1535-7163.MCT-06-0279

16. Benbrook DM, Lightfoot S, Ranger-Moore J, Liu T, Chengedza S, Berry WL et al (2008) Gene expression analysis of biological systems driving an organotypic model of endometrial carcinogenesis and chemoprevention. Gene Regulation and Systems Biology 2:21-42

17. Hotchkiss KA, Ashton AW, Klein RS, Lenzi ML, Zhu GH, Schwartz EL (2003) Mechanisms by which tumor cells and monocytes 
expressing the angiogenic factor thymidine phosphorylase mediate human endothelial cell migration. Cancer Res 63:527-533

18. Ikeda R, Che XF, Ushiyama M, Yamaguchi T, Okumura $H$, Nakajima $Y$ et al (2006) 2-Deoxy-D-ribose inhibits hypoxiainduced apoptosis by suppressing the phosphorylation of p38 MAPK. Biochem Biophys Res Commun 342:280-285 doi:10. 1016/j.bbrc.2006.01.142

19. Ikeda R, Furukawa T, Mitsuo R, Noguchi T, Kitazono M, Okumura $\mathrm{H}$ et al (2003) Thymidine phosphorylase inhibits apoptosis induced by cisplatin. Biochem Biophys Res Commun 301:358-363 doi:10.1016/S0006-291X(02)03034-6

20. Yee KO, Connolly CM, Duquette M, Kazerounian S, Washington R, Lawler J (2008) The effect of thrombospondin-1 on breast cancer metastasis. Breast Cancer Res Treat doi:10.1007/s10549$008-9992-6$

21. Lawler J (2002) Thrombospondin-1 as an endogenous inhibitor of angiogenesis and tumor growth. J Cell Mol Med 6:1-12 doi:10.1111/j.1582-4934.2002.tb00307.x

22. Margosio B, Rusnati M, Bonezzi K, Cordes BL, Annis DS, Urbinati $\mathrm{C}$ et al (2008) Fibroblast growth factor-2 binding to the thrombospondin-1 type III repeats, a novel antiangiogenic domain. Int J Biochem Cell Biol 40:700-709

23. Emeiss JJ, Edgell CJ (1988) Fibrinolytic properties of a human endothelial hybrid cell line (Ea.hy 926). Blood 71:1669-1675

24. Dozmorov I, Centola M (2003) An associative analysis of gene expression array data. Bioinformatics 19:204-211 doi:10.1093/ bioinformatics/19.2.204

25. Dozmorov I, Knowlton N, Tang Y, Shields A, Pathipvanich P, Jarvis $\mathrm{J}$ et al (2004) Hypervariable genes - experimental error or hidden dynamics. Nucleic Acids Res 32:e147 doi:10.1093/nar/gnh146
26. Livak KJ, Schmittgen TD (2001) Analysis of relative gene expression data using real-time quantitiave PCR and the $2^{-\Delta \Delta \mathrm{CT}}$ method. Methods 25:402-408 doi:meth.2001.1262/ meth.2001. 1262

27. Grant DS, Lelkes PI, Fukuda K, Kleinman HK (1991) Intracellular mechanisms involved in basement membrane induced blood vessel differentiation in vitro. In Vitro Cell Dev Biol 27A:327336 doi:10.1007/BF02630910

28. Kuo CJ, LaMontagne KRJ, Garcia-Cardena G, Ackley BD, Kalman D, Park S et al (2001) Oligomerization-dependent regulation of motility and morphogenesis by the collagen XVIII NC1/endostatin domain. J Cell Biol 152:1233-1246 doi:10.1083/ jcb.152.6.1233

29. Zhang Y, Hua Y, Benbrook DM, Covey JM, Chan KK (2006) High performance liquid chromatographic analysis and preclinical pharmacokinetics of the heteroarotinoid antitumor agent, SHetA2. Cancer Chemother Pharmacol 58:561-569 doi:10.1007/s00280006-0211-z

30. Rampazzo C, Fabris S, Franzolin E, Crovatto K, Frangini M, Bianchi V (2007) Mitochondrial thymidine kinase and the enzymatic network regulating thymidine triphosphate pools in cultured human cells. J Biol Chem 282:34758-34769 doi:10.1074/jbc.M705923200

31. Chengedza S, Liu T, Benbrook DM (2007) SHetA2 effects on thymidine phosphorylase and NF-KB activity. Proceedings of the AACR-NCI-EORTC International Conference on Molecular Targets and Cancer Therapeutics, San Diego, CA, USA

32. Chengedza S, Benbrook DM (2008) Effects of SHetA2 on IкBa and NF-kB in ovarian cancer cells: NF-kB. Keystone Symposium, Abstract\# 122, Banff, Alberta, Canada 